\title{
Correspondence
}

We welcome letters to the Editor concerning articles which have recently been published. Such letters will be subject to the usual stages of selection and editing; where appropriate the authors of the original article will be offered the opportunity to reply.

Letters should normally be under 300 words in length, double-spaced throughout, signed by all authors and fully referenced. The edited version will be returned for approval before publication.

\section{Outcome of Charnley total hip replacement across a single health region in England}

Sir,

The article in the July 1999 issue by Fender, Harper and Gregg ${ }^{1}$ entitled 'Outcome of Charnley total hip replacement across a single health region in England' was so interesting that I am stimulated to point out some of its implications and also request some amplification. American subscribers to the Journal are now faced with revolutionary changes in, and evolving plans for, health care. They bear directly on the subject.

There were 1198 'Charnley' total hip replacements (THR). Were other types of THR performed? Of these patients $19 \%$ were under 60 years of age. How many were aged 55 to 60 years? Charnley's large series included those in that age group. How many were under the age of 30 years since nowadays THR is carried out, even if only occasionally, in the young adult? Did the 1198 include any primary THRs in elderly patients with acute fractures? What was the prevalence of THR in the Trent population? Is there in Trent a 'specialist hospital' as mentioned in Table V?

It should be recalled that Charnley in his first decade of success with THR reported that "osteoarthritis was the commonest indication for THR with a minority of about 20 percent comprising rheumatoid arthritis and ankylosing spondylitis." 2 He also reported that "nearly all" of his thousands of patients operated on between 1960 and 1970 were over 55 years of age. Does this mean that under the NHS in the UK there has been little expansion of the application of THR (as in the USA) to other diagnoses and younger individuals? Charnley also reported a success rate of $90 \%$ while the authors record a lower rate of $73 \%$ if the hip score is the parameter. Exactly what does this mean? Is it that Charnley's overall regimen only included better prospects?

Orthopaedic surgeons in the USA are beset with existing restrictions on health care in general and on THR in particular. They would be well served if there was on record good evidence, in more detail than is provided in the cited article, of the epidemiological aspects of THR as illustrated in the questions asked above (and other analagous queries). While the authors are to be commended for initiating and completing this study, I would urge them to extend their investigation to develop a ten-year follow-up report in greater detail.

\section{J. COHEN (Cpt), MD}

Franciscan Children's Hospital and Rehabilitation Centre Boston, USA.

1. Fender D, Harper WM, Gregg PJ. Outcome of Charnley total hip replacement across a single health region in England. $J$ Bone Joint Surg [Br] 1999;81-B:577-81.

2. Eftekhar NS. Clin Orthop 1970;70:10.

\section{Authors' reply:}

Sir,

We thank Dr Cohen for his interest and very considered thoughts on our paper. In 1990, 2111 THRs were performed in the Trent region with a prevalence of approximately 50 per 100000 of the population. This entire cohort was studied at five years to assess the outcome of THR across the region. In total, 33 different acetabular and femoral components were used, $20 \%$ of which were uncemented. There were three 'specialist orthopaedic hospitals' within Trent in 1990, and the effect of the hospital environment along with a number of other variables on the outcome is being analysed at present. $^{2}$

Only one patient was under 30 years, $1 \%$ were under 40 years and $9 \%$ were aged 55 to 60 years. Acute fractures of the femoral neck accounted for $2.8 \%$ of the Charnley THRs performed. This indicates, as noted by Dr Cohen, that within the Trent region the Charnley THR is used predominantly for the older patient with osteoarthritis. The outcome across the whole region appears not to be as good as that reported in the literature and the data are being analysed to find factors which may explain this. Within Trent, younger patients with other indications for THR are undergoing surgery, but different types of prosthesis, often uncemented, are used.

We intend to publish more detailed results from this original study and hope that this will address some of the issues raised by Dr Cohen. We agree that this unique cohort of patients should have continued follow-up and we intend to do this at ten years.

\section{FENDER, FRCS}

P. J. GREGG, MD

University of Newcastle upon Tyne

Newcastle upon Tyne, UK.

1. Fender D, Harper WM, Gregg PJ. The 5 year outcome of total hip replacement (THR) across a single UK health region: results from a regional hip register. J Bone Joint Surg [Br] 1998;80-B:Suppl I:53.

2. Fender D, Harper WM, Gregg PJ. The effect of surgeon grade and consultant caseload on the five year outcome of Charnley total hip replacements (THR) across a single UK health region: results from a regional hip register. J Bone Joint Surg [Br] 1998;81-B:Suppl III:273.

Sir,

May I comment on the article in the July 1999 issue by Fender, Harper and Gregg' entitled 'Outcome of Charnley total hip replacement across a single health region in England.'
(C2000 British Editorial Society of Bone and Joint Surgery

0301-620X/00/110733 \$2.00

J Bone Joint Surg [Br] 2000;82-B:151-3. 
In the introduction the authors state that they assessed a large cohort of consecutive primary Charnley THRs to give an accurate outcome of the early results of this prosthesis. Would it be correct to suggest that a prosthesis itself cannot have an outcome? The functional outcome can be assessed. Since the authors neither define nor describe the technique of the Charnley low-friction operation as performed by various surgeons are they really measuring the early results of the prosthesis or merely the early results achieved with a particular surgical method?

They state that the Charnley total hip replacement (THR) has a long and established record and is regarded as one of the optimum implants, but is the test of the prosthesis really fair when subjected to an undefined surgical technique?

They point out that the early results of the use of the $3 \mathrm{M}$ hip prosthesis have again shown that new implants can be introduced and used in large numbers with potentially disastrous results. Although it may be acceptable to use 'implant' and 'prosthesis' interchangeably in a conversation it may not be acceptable in a scientific publication. These terms and the surgical technique must be clearly defined so that the source of the problem can be properly identified.

The relevance of these studies to an average orthopaedic surgeon in a non-specialist hospital is not known. They note that the relevance of any study is best judged by readers who find the information of interest and of benefit to their clinical practice. Are they now in a position to define 'an average orthopaedic surgeon' and is their study likely to be of relevance to an 'average orthopaedic surgeon'?

They again emphasise the need for a national register and surveillance of THRs. There is little doubt that follow-up of patients with THR is essential. Since clinical results may not reflect the mechanical state of the arthroplasty, ${ }^{3,4}$ study of the radiographs is essential. Whether this should be done locally or centrally is debatable.

A register of the type used by the authors would offer some information concerning outcome but would only tell us what has happened. Would it be impertinent to suggest that after nearly 37 years of the Charnley LFA we may in fact be in a position to suggest what should happen. Surely, prevention is much better than knowing what has happened and who has done it.

Finally, the initial description by Charnley ${ }^{5}$ does not refer to the Charnley low-friction arthroplasty as we know it today and as practised since November 1962.

\section{B. M. WROBLEWSKI, FRCS}

Wrightington Hospital

Wigan, UK.

1. Fender D, Harper WM, Gregg PJ. Outcome of Charnley total hip replacement across a single health region in England. $J$ Bone Joint Surg [Br] 1999;81-B:577-81.

2. Medical Device Agency. Hazard notice London: MDA, 1988 (MDA 9801).

3. Wroblewski BM, Siney PD, Raut VV, Taylor G. Charnley lowfriction arthroplasty 18 to 26 year results. J Bone Joint Surg $[\mathrm{Br}]$ 1992;74-B:Suppl II:140-1.

4. Wroblewski BM, Fleming PA, Siney PD. Charnley low-frictional torque arthroplasty 20- to 30-year results. J Bone Joint Surg [Br] 1999;81-B:427-30.

5. Charnley J. Arthroplasty of the hip: a new operation. Lancet 1961;i;1129-32.

\section{Authors' reply:}

Sir,

We thank Professor Wroblewski for his interest in our paper and for reminding us that total hip replacement (THR) involves a surgeon implanting a prosthesis into a patient! The purpose of our study was quite simply to report this activity, using the Charnley prosthesis, in the general setting of the NHS. There are numerous papers in the literature which inform us what the outcome of this activity may be when carried out in specialist centres. ${ }^{1-5}$ Our study, however, is unique in reporting the five-year results of outcome in the 'setting' in which most patients will receive this surgery. It therefore has great relevance to the present and future of THR in the NHS. We have identified a discrepancy in results between those in specialist centres and those obtained elsewhere. The important question is why and how can this be rectified?

D. FENDER, FRCS

P. J. GREGG, MD

University of Newcastle upon Tyne

Newcastle upon Tyne, UK.

1. Wroblewski BM, Siney PD. Charnley low-friction arthroplasty of the hip: long-term results. Clin Orthop 1993;292:191-201.

2. Eftekhar NS. Long-term results of cemented total hip arthroplasty. Clin Orthop 1987;225:207-17.

3. Salvati EA, Wilson PD Jr, Jolley MN, et al. A ten-year follow-up of our first one hundred consecutive Charnley total hip replacements. $J$ Bone Joint Surg [Am] 1981;63-A:753-67.

4. Schulte KR, Callaghan JJ, Kelley SS, Johnson RC. The outcome of Charnley total hip arthroplasty with cement after a minimum twentyyear follow up. J Bone Joint Surg [Am] 1993;75-A:961-75.

5. Wroblewski BM. 15-21-year results of Charnley low-friction arthroplasty. Clin Orthop 1986;211:30-5.

\section{Biomechanical comparison of fixation of type-I fractures of the lateral tibial plateau}

Sir,

I read with interest the paper in the May 1999 issue by Parker et $\mathrm{al}^{1}$ entitled 'Biomechanical comparison of fixation of type-I fractures of the lateral tibial plateau.'

The study compared yield loads between fractures fixed by three cancellous lag screws or two lag screws and an antiglide screw with nine paired control fractures which were fixed by two cancellous lag screws. The authors reported that no statistically significant differences were found, and concluded that "no advantage is provided by the addition of a third lag screw or an antiglide screw in the fixation of type-I split fractures of the lateral plateau".

Unfortunately, this study was flawed by two major statistical errors

With a sample size of nine it would only detect differences in mean yield load of $270 \mathrm{~N}$ with $90 \%$ power. This is reflected in the size of the $95 \%$ confidence intervals for the difference between the sample means $(-123 \mathrm{~N}$ to $277 \mathrm{~N}$ for three screws, and $-51 \mathrm{~N}$ to $155 \mathrm{~N}$ for the antiglide screw). To detect differences of $50 \mathrm{~N}$ a sample size of 263 would have been necessary.

The authors compared their data using the paired Student $t$-test. Since, however, the data are not normally distributed (Lilliefors test, $\mathrm{p}=0.001$ ) non-parametric analyses should have been used.

It is quite possible that there are clinically significant differences in the yield loads of the three different methods of fixation, but this study was of insufficient power to detect them, and a typeII statistical error occurred. This was further compounded by the use of inappropriate analyses. The results of this study should therefore be interpreted with caution, and further larger studies are needed to assess whether the addition of a third lag screw or an antiglide screw is of value.

S. A. EARNSHAW, FRCS

King's Mill Hospital

Sutton-in-Ashfield, UK 
1. Parker PJ, Tepper KB, Brumback RJ, Novak VP, Belkoff SM. Biomechanical comparison of fixation of type-I fractures of the lateral tibial plateau: is the antiglide screw effective? J Bone Joint Surg [Br] 1999;81-B:478-80.

\section{Authors' reply:}

Sir,

We thank Mr Earnshaw for his comments on our article.

You are correct in stating that small sample sizes often result in data which are not normally distributed. In these cases, nonparametric tests are indicated. We repeated the analysis of our data using the Wilcoxon signed-rank test, and it indicated no significant differences between the antiglide-screw or three-screw fixations and their respective controls (two-screw fixations).

Your point about statistical power is well taken and illustrates the implications of applying biomechanical data and statistical analysis blindly to clinical practice. Although evaluating 263 paired tibiae may have given sufficient statistical power to show significance, the question would still remain as to whether a difference of $50 \mathrm{~N}$ between treatments was clinically relevant. We doubt that increasing the fixation strength by $50 \mathrm{~N}$, approximately $6 \%$ of the body-weight of a $70 \mathrm{~kg}$ individual, would be clinically significant, even if shown to be statistically significant. In addition, obtaining 263 paired tibiae for this purpose would be a phenomenal waste of resources. The cost of the tibiae alone, not to mention the fees for personnel and laboratory time, would be in excess of $\$ 36000$ ( $£ 24000$ ).

We believe that because the Wilcoxon test indicated no significant differences, our conclusions are justified.

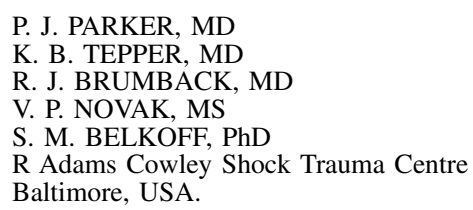

\section{Planar anteversion of the acetabular cup as determined from plain anteroposterior radiographs}

Sir,

May I comment on the publication in the May 1999 issue by Pradhan ${ }^{1}$ entitled 'Planar anteversion of the acetabular cup as determined from plain anteroposterior radiographs.'

Attempts at assessing anteversion/retroversion of the cup in total hip arthroplasty on a single radiograph are not new. The first of which I am aware was in a discussion which took place between the late Professor Sir John Charnley and Professor Maurice Müller when the latter visited Wrightington Hospital in January 1970. As a result I suggested that a second semicircular wire, the anteversion marker, be placed along the anterior rim of the cup at right angles to the wear marker already introduced. The relative insensitivity of this marker to the changes in version of the cup was pointed out by Charnley. ${ }^{2}$ The initial movement takes place almost in line with the x-ray beam. The extreme sensitivity of the anteversion marker was appreciated from the very beginning since in changes in version of the cup the path of the anteversion marker is across the $\mathrm{x}$-ray beam. This has been described in detail since, ${ }^{3}$ and although good interobserver consistency can be achieved when examining an individual radiograph, it is difficult to achieve a consistence of radiography for an individual case.

Pradhan's suggestion, although of interest, is merely an extension of what is already known, since the formula described does not differentiate anteversion from retroversion. ${ }^{1}$ An anteroposterior radiograph is not sufficient when the cup is retroverted. To distinguish the two, a lateral radiograph is essential. Has the problem arisen because a symmetrically manufactured cup has been placed in a position where asymmetry of both structure with function is the feature? Would it be more correct to suggest that the normal human acetabulum is not anteverted but asymmetrical with freedom of flexion, adduction and internal rotation and stability in the opposite direction. If this is the case why not mimic the natural structure and function by an appropriate cup design such as the angle bore cup. ${ }^{4}$ The anterior chamfer takes care of the 'anteversion', the posterosuperior recess offers stability in flexion, adduction and internal rotation while the anteversion marker gives some indication of cup version.

\section{B. M. WROBLEWSKI, FRCS}

Wrightington Hospital

Wigan, UK

1. Pradhan R. Planar anteversion of the acetabular cup as obtained from plain anteroposterior radiographs. $J$ Bone Joint Surg $[\mathrm{Br}]$ 1999;81-B:431-5.

2. Charnley J. Low friction arthroplasty of the hip: theory and practice. Berlin, etc: Springer-Verlag, 1979;324-7.

3. Wroblewski BM. Revision surgery in total hip arthroplasty. London, etc: Springer-Verlag, 1990:35-7.

4. Wroblewski BM. Revision surgery in total hip arthroplasty. London, etc: Springer-Verlag, 1990:43.

\section{Author's reply:}

Sir,

I thank Professor Wroblewski for his wise comments on my article. I agree with him that the method described calculates the extent of 'version' of the acetabular cup and does not describe 'ante-' from 'retro-' version. I have pointed out in my article that another anteroposterior radiograph of the hip with rotation of the pelvis to the opposite side should differentiate between the two.

With regard to the difficulty of producing a consistent anteroposterior radiograph in the same patient, studies which show variation in acetabular version have involved centring the $\mathrm{x}$-ray beam on points as wide apart as the sacral promontory, the crest of the wing of the ilium and the pubic symphysis. ${ }^{1}$ While determining acetabular version, if centring is routinely done in the region of the midinguinal point, the error could be greatly minimised.

I find Professor Wroblewski's idea of an 'angle bore cup' fascinating and acknowledge his early contribution to the introduction of anteversion markers in the cup.

\section{R. PRADHAN, MS ORTH, FRCS}

Royal Surrey County Hospital

Guildford, UK.

1. Goergen TG, Resnick D. Evaluation of acetabular anteversion following total hip arthroplasty: necessity of proper centring. Br J Radiol $1975 ; 48: 259-60$ 